\title{
The Study of Food Safety Information Platform Construction
}

\author{
Dehai Shen ${ }^{\mathrm{a}}$, Jian Hou ${ }^{\mathrm{b}}, \mathrm{Xu} \mathrm{E}^{\mathrm{c}}$, Longchang Zhang ${ }^{\mathrm{d}}$, Qi Yan ${ }^{\mathrm{e}}$
}

College of Information Science and Technology, Bohai University, Jinzhou, Liaoning 121013, China

ashendh25@qq.com, bjian_hou@163.com, 'exu21@163.com, d22427291@qq.com, e32392392@qq.com

Keywords: food security, information platform, traceability, integrity, module

Abstract. Food safety events continue to emerge in China, which exposures the issues existing in food safety supervision and food safety information service. We should explore and research the rational solution to track the process of food production and circulation of the chain, to release and collect information about food safety timely has become a key to sustained and healthy development of China's food industry. Establishing a normative and perfect food safety information platform can improve the work efficiency of food safety supervision and can enhance the transparency of food production and circulation, which is convenient for the public to query food safety information and feedback. A food safety information platform structure is designed, and related its functions, analyzed problems in platform construction, and put forward some construction suggestions.

\section{Introduction}

With the rapid development of China's economy, people's living standard has been greatly improved, and their consumption demand for food is an unprecedented strong, however, because of the interests driven and lack of food regulation caused a series of successive major food safety incidents. People's concerns for food safety have reached the unprecedented extent, food safety has become a hot topic in the whole society and the world. It is an important task of informatization construction for countries and regions all over the world to establish a perfect information-based platform and gradually replace the traditional management system. A well-developed food safety information platform helps to improve the efficiency of regulatory work, enhance the transparency of food production and circulation and enterprise's main body responsibility, can improve the food safety consciousness and intensify propaganda and public participation.

\section{Overview of food safety information}

Food safety information refers to the relevant information which be recorded or saved in a certain form in the process of food production, circulation, food consumption and import and export [1], the sources of information including food supervision departments and related government departments. Food safety information is mainly divided into the following categories: food safety laws and regulations information; food safety events; food safety supervision and inspection information; food safety education and training information; food enterprise information and product information; food safety warning information; food safety credit information. Food safety information is the main data source to construct the food safety information platform, and its effective management and release has a pivotal role in the progress of the food safety work. Food safety information is the main data source to construct the food safety information platform, and its effective management and release has a pivotal role in the progress of the food safety work. 


\section{The structure of food safety information platform}

The food safety information platform is a working platform which can provide a data sharing and information integration for the various functional departments, it makes the division and cooperation more effective for various regulatory authorities, and provides many unified, standards and authoritative food safety information for public. The platform should include six systems, the structure is shown in Figure1.

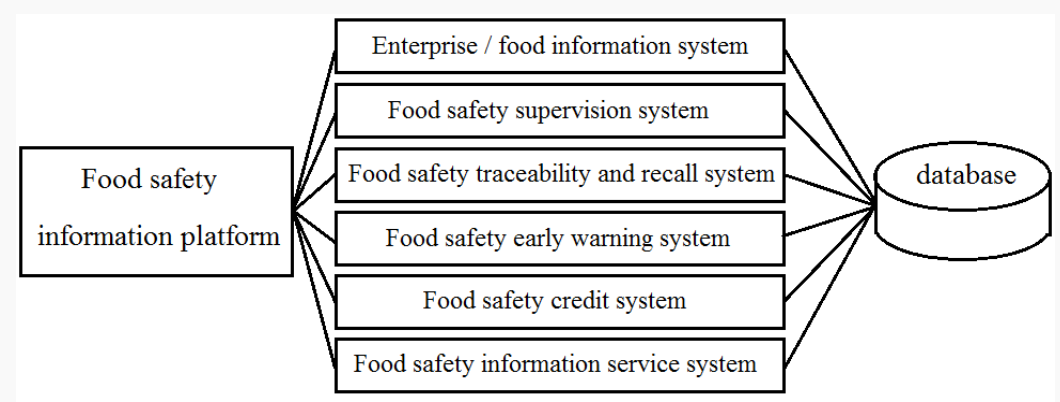

Fig.1 structure of food safety information platform

Enterprise / food information system. The system collects and manages food information and information of the enterprises who product and operate food. The relevant regulatory authorities can register, query and update the basic information about enterprises and food through the system. Through data sharing and interface, the system can provide traceability information for food traceability system. The system includes enterprise information module and food information module.

Food safety supervision system. The system collects and manages the specific food safety information. The food safety supervision departments obtain the food safety information data (such as pesticide residues, whether expired, additives is safe or not, whether or not containing toxic substances) through various monitoring means directly and food sampling survey information through the market survey and interview, at last, the information will be stored, collected and analyzed, those unsafe information monitored will be reported timely. The system provides the basis data to the food safety traceability and recall system and the food safety warning system.

Food safety traceability and recall system. The system collects production and circulation information of each kind of food, storages and manages them, to finish the track the whole food production, circulation and each link of the chain. The system can quickly and effectively find the problem occurred or related materials and sources when food quality problems are found, and can recall the food when necessary [2]. Relevant department will implement strict punitive measures on Enterprises involved, which can monitor the food production and circulation effectively [3]. The system includes two modules: food traceability module and food recall module.

Food safety early warning system. The system collects food safety monitoring data from the food safety supervision system, then carries on comprehensive analysis and evaluation, provides early warning suggestions, releases early warning information and starts emergency plans [4].

Food safety credit system. The system entries and manages credit rating of food production enterprises, food circulation enterprises and food sale enterprises. Enterprise credit rating is evaluated by the relevant government departments according to the enterprise quality credit supervision system. The system adopts the method of classification regulation, the lower credit 
rating enterprise will be notified and required rectification. Enterprises which have serious quality problems or have had a major food quality and safety incidents will be severely punished and incorporated into the "black list" and will also be announced through the media.

Food safety information service system. The system mainly faces to the public, its tasks include publishing and querying all kinds of food safety information, collecting feedback and reporting information, implementing food safety education and training, etc. The published information includes the overall situation of China's food safety, food supervision and inspection information, food safety warning information, food safety event information and food safety integrity information, etc. The public can browse such information through the system, can query the enterprise basic information, food basic information and the enterprise integrity information, can feedback the information, and report the issues food and enterprises, and can receive training.

\section{Existing problems in the construction of food safety information platform in China}

China's food safety information platform is divided into national, provincial, municipal and county four levels, the current food safety information platform mainly includes such systems: the National Food Quality and Safety Nets and its sub-stations, the National Food(Product) Safety Traceability Platform and some provincial traceability platforms (Shandong, Xinjiang, Sichuan), food safe information network in each provincials. Generally speaking, the main problems in the construction of food safety information platform in China are as follows.

(1) Information management is disordered, information sharing is poor. China's food safety information comes from different departments, there are serious unit split between departments, sharing coordination mechanism is not perfect, which causes insufficient information resources and results in low resources utilization and waste of investment.

(2) The pace of construction of the platform is uneven. Food safety information networks in some provinces are such websites only about food and drug administration, such as Guizhou, Jilin, etc., the platform has not really been established.

(3) The functions in module are not comprehensive. Some systems lack public participation plate and report plate, some systems are short of food information related module, such as Jiangsu Food Network mainly consists medicines, health products and cosmetics information, some sites lack security early warning information.

(4) Some food website's performance is not stable, and system data update slowly.

(5) There are few detail information chains and insufficient information in the traceability platform.

\section{Countermeasures about construction of food safety information platform}

In recent years, China has accelerated the pace of the food safety information platform construction, it can be seen that China has attached great importance to food safety issues at present, but due to lack of unified deployment, overall planning and construction experience, the quality of the platform at all levels is uneven, according to the analysis of actual situation, the following construction strategies are proposed.

(1) Unifying platform construction standards. The state should introduce a unified platform construction standard which is conducive to data sharing between the various platforms, and is beneficial for overall food safety information collection, processing and analysis for the country, can reduce the construction funds. 
(2) Learning from the advanced experience of foreign countries. The United States, Europe and some other countries started earlier in the construction of food safety information platform, and with more perfect platform, China should draw on their construction experience.

(3) Increasing capital investment. Food safety information platform is a multi functions network platform based on computer and network technology, it includes a number of subsystems, and the use of the platform involves many departments, so the platform construction is a complex computer systems engineering, its success needs to invest a lot of money and manpower.

(4) Making clear division of labor between departments, strengthening the cooperation between departments. There is a data sharing relationship between subsystems of food safety information platform, if data in one department arises problem, the result will affect the corresponding work of other departments directly, so the division of labor and cooperation are very necessary.

\section{Conclusions}

China's food safety information platform construction is an important livelihood project, the state should make overall plans and steadily push forward the project. A perfect food safety information platform can promote to the healthy and rapid development of China's food industry, and is helpful for the improvement of people's life quality, and provides an important guarantee for the construction of a harmonious society.

\section{Acknowledgement}

The project is sponsored by National Nature Science Foundation (61473045), Natural Science Foundation of Liaoning Province(2014020141).

\section{References}

[1] Wan Qian, Xue Ming. Mixed Adaptive Image Denoising Algorithm Based on Noise Isolation and Wavelet Thresholding. Electronic Sci. \& Tech, vol.24, no.5, p.94-97,2011, (In Chinese).

[1] Li Lei, Zhou Sheng-sheng. Status of the Establishment for Chinese Food Safety Information Exchange Platform. Food Industry, no.12, p. 78-82,2011, (In Chinese).

[2] BAI Hong-wu, SUN Ai-dong, CHEN Jun .Agricultural products traceability system for quality and safety based on internet of things. Jiangsu Journal of Agricultural Science, vol.29, no.2, p.415-420, 2013, (In Chinese).

[3] LONG Hong, MEI Can-hui. Development Status and Proposal of Pre-warning System and Traceability System of Food Safety in China. Modern Food Science and Technology, vol.28,no.9, p.1256-1261,2012, (In Chinese).

[4] LI Hong-wei , HUANG Wei-dong , HONG Xiao-juan. Research on Ontology Building in Food

Security Pre-warning. Computer Technology and Development, vol.23,no.9,p.238-240,244,2013, (In Chinese). 